\title{
SPATIO-TEMPORAL LAND USE CHANGE ANALYSIS IN DIRECTIONAL ZONES OF LUCKNOW CITY, INDIA
}

\author{
Ravi Verma ${ }^{\text {a }}$, P. K. Garg ${ }^{\text {a }}$ \\ ${ }^{a}$ Department of Civil Engineering, Indian Institute of Technology Roorkee, Roorkee-247667, Uttarakhand, India - \\ rverma2@ce.iitr.ac.in
}

KEY WORDS: Spatio-temporal, Land use change, Landscape Metrics, Shannon's entropy, Urban growth types, Lucknow.

\begin{abstract}
:
Dynamic changes in urbanisation of a city is best analyzed through spatio-temporal analysis of classified data. Decadal Land use data for India for years 1985, 1995 and 2005 and Copernicus Global Land service Dynamic Land Cover layers (CGLS-LC100 products) for year 2015 have been used to conduct analysis for multi-temporal analysis of urban expansion and its dynamics using Landscape Metrics by FRAGSTATS and Shannon's Entropy Values $\left(H_{n}\right)$ over the 4 directional zones of Lucknow city namely North-East (NE), South-East (SE), South-West (SW) and North-West (NW). The metrics used to find characteristics of urbanisation are Landscape Shape Index (LSI), Largest Patch Index (LPI), Mean Euclidean Nearest Neighbor Distance (ENN_MN) and Aggregation Index (AI). Results showed the increase in LSI for Built-up patches over the years from 1985 to 2015, explaining the increase in complexity of shapes of Built-up patches in all zones. The increase in LPI indicates the increase of Built-up land use class over the years but also the convergence of urbanisation in the study area as indicated by lower entropy values. NW zone of Lucknow city area being poor in Vegetation is having highest ENN_MN which is decreasing over the years indicating more centrality. AI is same for Built-up patches from 1985 to 2015 which is due to either edge-filling or outlying urban growth in study area in all 3 change durations 1985-1995, 1995-2005 and 2005-2015. Among all 4 zones of Lucknow city, decrease in vegetation is major factor to urbanisation in city over the years.
\end{abstract}

\section{INTRODUCTION}

Modern tool and techniques are helping in modelling and monitoring of urbanisation in metropolitan cities all over the world (Sapena and Ruiz, 2015). Urbanisation is an event, upon unfolding of which landscape of city becomes more diverse in land use (Liu et al. 2016). Study of landscape patterns in context of urbanisation is an effective method to plan urban sustainability (Yang et al. 2019). Zonal-Gradient approach can be efficient one to materialise the spatial patterns of urbanisation at local level (Ramachandra and Aithal, 2013). At general, urban fringes in cities of Asian countries wary more widely but Indian Cities in lack of state policies of urban sprawl are more irregular and convoluted (Huang et al. 2007). To capture the typicality and intrinsic features of urban sprawl of an individual city, a geo-spatial index is the best indicator (Jiang et al. 2007).

Studies of urban sprawl mainly consists of its two aspects first being qualitative, by analysing spatial metrics and second being quantitative by analysing expansion parameters (Huang et al. 2007 and Maimaiti et al. 2017). Spatial metrics and its rightful analysis of urban sprawl may prove beneficial for any city in its future planning and augmentation of settlement policies (Berling-Wolff and Wu, 2004a). Spatial metrics are best known for indicating sprawl characteristics at micro scale of neighbourhood level with temporal resolution (Ramachandra et al. 2019). In terms of Indian cities to collaborate the effect of population on urbanisation several studies have been performed with help of Shannon's Entropy value (Bhatta, 2009 and Jat et al. 2008). The four characteristics of urban sprawl which should be explained by use of combination of any spatial metrics are complexity, compactness, centrality and porosity (Ji et al. 2006 and Jiang et al. 2007). These matrices introduced by McGarigal and Marks, 1995 show us the form of urbanisation taking in different directions and years. The effect of resolution of classified images is insignificant in spatio-temporal analysis of spatial metrics (Wu et al. 2011).

It has been attempted to best describe these characteristics was successfully made by characterising urban growth in 5 different types as in infilling, extension, linear development, sprawl and large-scale projects (Camagni et al. 2002). Raw information about infill, expansion, isolated, linear branch and clustered type of urban growth was introduced utilizing non-developed land also in change analysis (Wilson et al. 2003). Spontaneous, diffusive, organic and road influenced type of urban growth is another form to best describe change in ULUS (Berling-Wolff and $\mathrm{Wu}, 2004 \mathrm{~b})$. Urban growth type was classified into basically 3 types Edge-expansion, Infilling and Outlying using equation involving common perimeter of new and old urban patch (Xu et al. 2007) and using Landscape Expansion Index (LEI), calculated by common area lying in buffer around new and old urban patches (Liu et al. 2010). Simulation of LEI with the help of Cellular Automata (CA) was proposed and result showed it (LEI-CA) performing better than LEI (Liu et al. 2014). An attempt to modify three growth types was made by introducing extra Ribbon type of urban patches by classifying perimeter equation into 4 classes (Shukla \& Jain, 2019). The shift in dominance of urban growth types in study area is inevitable over the course of change duration ( $\mathrm{Li}$ et al. 2013). Edge- expansion type of urban growth has been shown in 
dominant in previous studies (Sun et al. 2013 and Wu et al. 2016).

\section{STUDY AREA}

The local effect of urbanisation is not taken into account here but the study of the directionality of urbanisation helped in understanding the management of characteristics of it (Ramchandra et al. 2012). Keeping this point in mind study area of Lucknow city is chosen and divided into 4 directional zones of North-East (NE), South-East (SE), South-West (SW) and North-West (NW) Figure 1.

Study area is a part of Lucknow city in Uttar Pradesh state of India. It is Lucknow Development Authority (LDA) of area approximately $1232.64 \mathrm{~km}^{2}$. It is comprising a river named Gomati, flowing throughout the city, a canal and a reserved forest by the name of Kukrail Reserve Forest area for crocodiles. Each zone comprises of almost same area, NE being smallest in area $\left(280.67 \mathrm{~km}^{2}\right)$ and SW being largest $(336.14$ $\left.\mathrm{km}^{2}\right)$. SE is just bigger than NE $\left(290.55 \mathrm{~km}^{2}\right)$ and NW is just a little smaller than SW $\left(325.08 \mathrm{~km}^{2}\right)$.

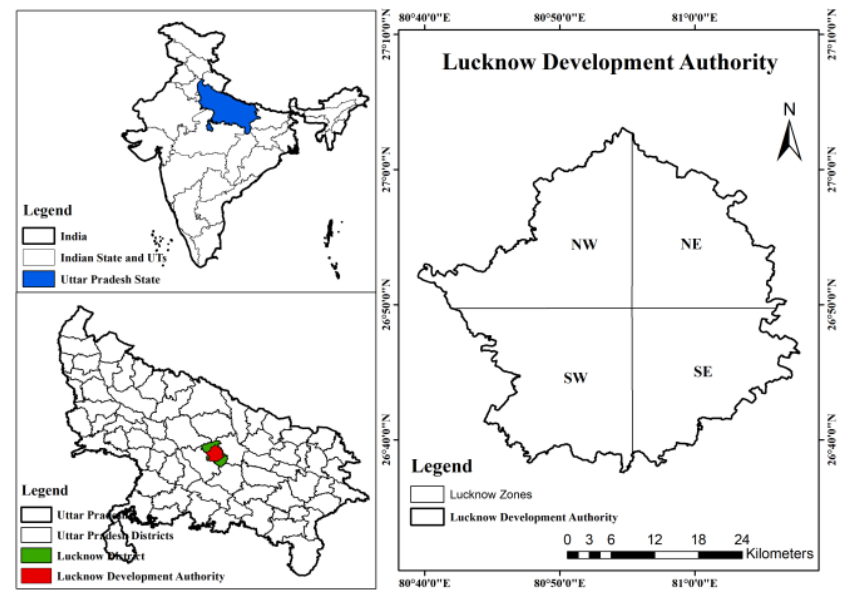

Figure 1. Study area used in study.

\section{METHODOLOGY}

The study has been performed to study the effects of urbanisation in different directional zones of study area.

\subsection{Data used}

Decadal Land use data of India (Roy et al. 2016) for years 1985 , 1995 and 2005 has been used and Copernicus Global Land service Dynamic Land Cover layers at $100 \mathrm{~m}$ resolution (CGLSLC100 products) data (Buchhorn et al. 2020) for year 2015 has been used as classified maps for study area.

CGLS-LC100 product is obtained via Google Earth Engine (GEE) and Decadal Land use data if India has been downloaded from ORNL DAAC website.

Copernicus Global Land service Dynamic Land Cover layer is re-projected for ESPG 4326 geographic latitude/longitude coordinate reference system (CRS) while obtaining from GEE only.

\subsection{Work flow of study}

Since, the data obtained as classified images, both Decadal ORNL DAAC images and CGLS-LC100 product are of same resolution i.e. $100 \mathrm{~m}$ resolution, all the images are clipped for study area for further analysis.

ORNL DAAC decadal LULC images contain 17 and 9 land use classes in Indian Territory and study area boundary respectively. Table 1 shows these 9 classes, which are reclassified into 5 useful classes for analysis purpose in this study.

Likewise, CGLS-LC100 product obtained from GEE for study area also contain 11 land use classes, which are reclassified into 5 useful classes, same as in ORNL DAAC data reclassification in Table 1 for analysis purpose in this study.

Table 1. Land use classes defined in study.

\begin{tabular}{|c|c|c|}
\hline $\begin{array}{c}\text { Land use } \\
\text { class used } \\
\text { in study }\end{array}$ & $\begin{array}{c}\text { Land Use classes } \\
\text { merged in Decadal } \\
\text { ORNL DAAC data }\end{array}$ & $\begin{array}{c}\text { Land Use classes } \\
\text { merged in CGLS- } \\
\text { LC100 product }\end{array}$ \\
\hline Built-up & Built-up Land & Built-up \\
\hline Vegetation & $\begin{array}{c}\text { Deciduous } \\
\text { Broadleaf Forest, } \\
\text { Shrub land and } \\
\text { Plantations }\end{array}$ & $\begin{array}{c}\text { Shrubs, Herbaceous } \\
\text { vegetation, Closed } \\
\text { forest, deciduous } \\
\text { broad leaf/ not } \\
\text { matching any of the } \\
\text { other definitions and } \\
\text { Open forest, } \\
\text { deciduous broad leaf/ } \\
\text { not matching any of } \\
\text { the other definitions }\end{array}$ \\
\hline Water & Water Bodies & $\begin{array}{c}\text { Permanent water } \\
\text { bodies }\end{array}$ \\
\hline Agricultural & Cropland & $\begin{array}{c}\text { Cultivated and } \\
\text { managed vegetation / } \\
\text { agriculture }\end{array}$ \\
\hline Other & $\begin{array}{c}\text { Fallow Land, } \\
\text { Wasteland and } \\
\text { Permanent } \\
\text { Wetlands }\end{array}$ & $\begin{array}{c}\text { Bare / sparse } \\
\text { vegetation and } \\
\text { Herbaceous wetland }\end{array}$ \\
\hline
\end{tabular}

These classified images obtained are shown in Figure 3. These images are used to classify the built-up patches in the three below categories (Figure 5) shown in eq. 1, with the help of a field "R", shown in eq. 2.

$$
R=\left\{\begin{array}{cc}
\text { Outlying } & ; R=0 \\
\text { Edge-expansion } ; 0<R \leq 0.5 \\
\text { Infiling } & ; R>0.5
\end{array}\right.
$$

When the new built-up patch is lying in inside perimeter of old built-up patch, $\mathrm{R}$ becomes greater than 0.5 , as length of common edge in utmost condition be equal to perimeter of new built-up patch and hence it will be called infilling, whereas when new built-up patch is lying spread at edges of old built-up patch, $\mathrm{R}$ lies between 0 and 0.5 and hence it will be called edgeexpansion. Outlying built-up patches are those which area having no common edge from old built-up patch, so $\mathrm{R}$ automatically becomes 0 for it. The $\mathrm{R}$ ranges from 0 to 1 .

$$
R=\frac{L_{c}}{L}
$$

Where, Lc is length of common edge between old and new built-up patch and $\mathrm{L}$ is perimeter of new built-up patch (Xu et al. 2007). Study of urbanisation is knowing the dominance 
between these three urban growths (Liu et al. 2016), as it helps in understanding the heterogeneity of urban sprawl in study area.

Landscape metrics help quantifying the properties of spatial distribution of landscape, patches and its classes. Complexity, centrality, compactness and porosity are properties which have been quantified to describe the landscape of study area.

Landscape shape Index (LSI) has been used to measure complexity of landscape as complexity denotes the irregularity in size of patches. Centrality is quantified by Mean Euclidean Nearest-Neighbor distance (ENN_MN). The Mean Euclidean Nearest-Neighbor distance (ENN_MN) measures the Euclidean distance of a patch from nearest patch in neighborhood. It may be the shortest edge to edge distance between patches of all class in landscape. Aggregation Index (AI) helps in quantifying the compactness of patches in landscape.

Compactness measures the distribution of patches of alike properties which may depend upon patch shape and distance also. Porosity is measured as ratio of open space in comparison to total built-up area in landscape. LPI (Largest patch index) helps in determining the pattern of landscape in continuity. These indices can be calculated using FRAGSTATS (McGarigal \& Marks, 1995) as listed below (Figure 4).

GeoTIFF files of classified images of year 1985 to 2015 were used in batch process in FRAGSTATS for calculation of Class and Landscape Metrics then pattern was analysed for urbanisation in study area over change durations and 4 different zones.

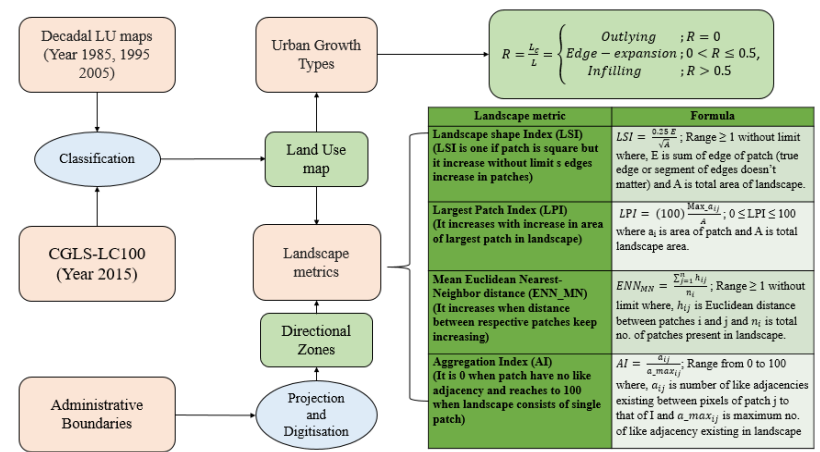

Figure 2. Flow chart showing methodology used in study.

Shannon's Entropy $\left(H_{n}\right)$ is one of the widely used index to measure urban sprawl. It provides a perspective of directional growth of urban area in ' $n$ ' zones of landscape (Ramachandra and Aithal, 2013). Shannon's entropy can be calculated as below by eq. 3 .

$$
H_{n}=-\sum_{i=1}^{n} P_{1} \log P_{i}
$$

Where, $\mathrm{n}$ is the no. of zones in study area, which in this study has been 5 Assembly constituencies of Lucknow city and $\mathrm{P}_{i}$ is the proportion of built-up area in the zone, so $\mathrm{P}_{i}$ can be describes as ratio of built-up area to the total area of zone. Shannon's entropy ranges from 0 to $\log (n)$ and depicts distribution of built-up area in zone. Higher the $H_{n}$ value, i.e. nearer the $H_{n}$ value to $\log (n)$, more is the dispersion in built-up of zone depicting characteristics of urban sprawl in zone.

\section{ANALYSIS OF RESULTS \& DISCUSSION}

\subsection{Land Use Change}

\subsubsection{Land use change direction}

LDA over the period of 30 years has changed a vast urbanisation in it. Due to increase in boundary of LDA region in Lucknow city agricultural class also appears in great numbers in terms of area in it in early durations like 1985 and 1995 but later years due to vast urbanisation taking place in years 2005 and 2015 Built-up class overcomes it in the region.

Indira canal at southern part of region is intact from start of study year 1985 to end year 2015 but Gomati River passing through city has been depleted in large numbers due to accumulation of sludge and leaves on its path and along its banks.

Southern part of LDA region is comprising an industrial area of city known as Lucknow Industrial Development Authority (LIDA), that's why Other/Barren class is dominant in this part of the study area.

Vegetation class has suffered worst in the study area, due to urbanisation and conversion into agricultural land. In 1985 a patch of vegetation showing at centre of city is Cantonment area which gets depleted throughout the years into built-up class. The only region of vegetation which is intact over whole period of study is Kukrail Reserve Forest Area in NE zone of study area.

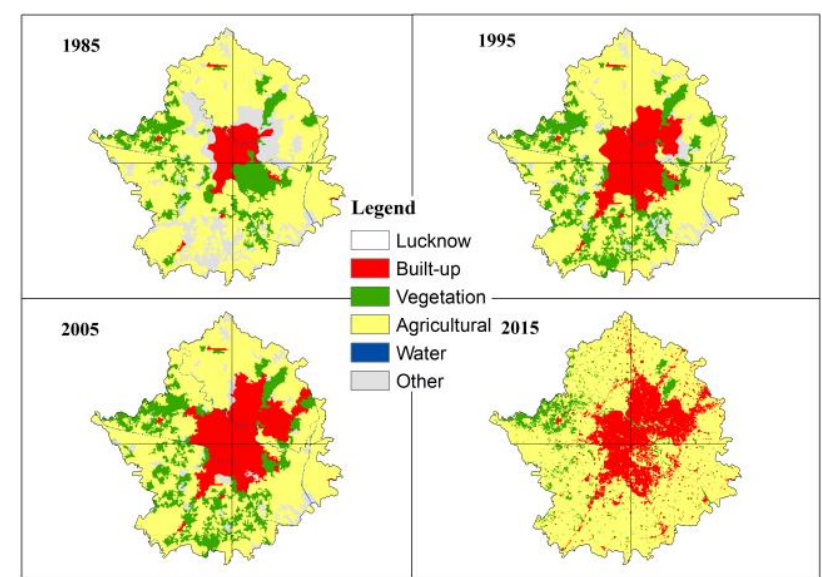

Figure 3. Classified maps of study area in different years.

\subsubsection{Land Use change Magnitude}

Figure 4 shows that largest change in any land use class has been in Built-up class in study area of almost $176 \mathrm{~km}^{2}$. Change in Other land use class has also been significant over the period of 30 years but the difference in classification scheme of ORNL DAAC Decadal Land use Land Cover for India and CGLS 100 products may be the reason behind it. Decrease in vegetation has contributed to both increase in Built-up and Agricultural land use class in study area (Table 2). Conversion of Agricultural land use class to Vegetation land use class also took from 1985 to 2015 in some amount but it wasn't even close to reverse process and hence there has been decrease of almost 50\% to its original amount in year 1985 to year 2015 . 
Table 2. Change Matrix for Land use classes for 1985 to 2015.

\begin{tabular}{|l|r|r|r|r|r|r|r|r|}
\hline LU Classes & Built-up & \multicolumn{1}{|c|}{ Vegetation } & \multicolumn{3}{|c|}{ Agricultura Water } & \multicolumn{1}{c|}{ Other } & $\mathbf{1 9 8 5}$ Decreased \\
\hline Built-up & 66.25 & 1.97 & 6.91 & 0.38 & 0.22 & 76.24 & 9.99 \\
\hline Vegetation & 32.57 & 43.59 & 95.12 & 0.44 & 0.06 & 173.31 & 140.74 \\
\hline Agricultural & 92.98 & 32.97 & 652.02 & 3.56 & 0.33 & 790.14 & 697.16 \\
\hline Water & 0.61 & 1.01 & 4.10 & 3.10 & 0.29 & 9.2 & 8.59 \\
\hline Other & 56.97 & 6.60 & 117.83 & 0.61 & 0.22 & 183.75 & 126.78 \\
\hline & $\mathbf{2 0 1 5}$ & 252.53 & 87.18 & 883.37 & 8.45 & 1.11 & 765.18 & \\
\hline Increased & 186.28 & 85.21 & 876.46 & 8.07 & 0.89 & & \\
\hline
\end{tabular}

There has been barely any change in Water land use class in study area but in year 2015 it had a little decrease which may be due to covering of river Gomati by plantations and drying of it at some places in study area (Figure 4). Agricultural land use class had contribution from Vegetation and Other/Barren land use class all over the study periods from 1985 to 2015 (Table 2). Extension of LDA boundary to accommodate more villages in later stages of study area by local authorities may be a major factor in this large contribution to increase in Agricultural land to study area.

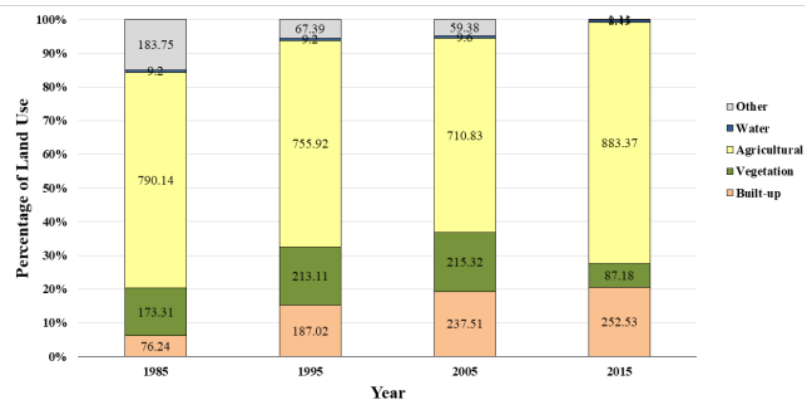

Figure 4. Magnitude of Land use change in study area

\subsection{Urban Growth type}

Urbanisation in LDA region for its directional zones has seen quite a similar pattern over the change durations of 1985-1955, 1955-2005, 2005-2015 and also in 1985-2015. Infilling type of urban growth is absent in all these above change durations and Edge-expansion type of urban growth seems quite present all over the study area in Figure 5.

Outlying type of urban growth is only seen in study area in change duration 2005-2015 indicating a dispersed growth in this duration in study area. These outlying patches of Built-up class in change duration 2005-2015 causing dispersed growth in study area lie with the fact that there has been a little increase in Built-up land use class in year 2015 from 2005, i.e. of only $1.25 \%$.

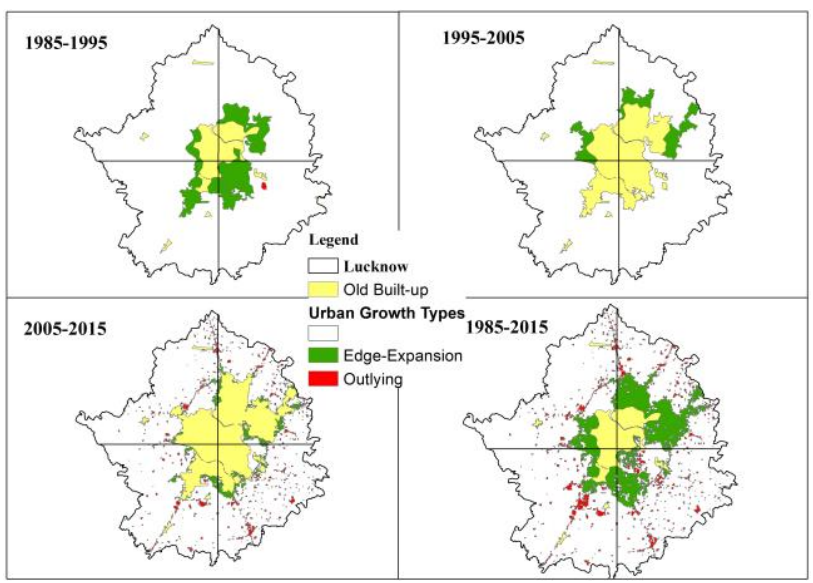

Figure 5. Types of Urban growth in different years.

\subsection{Landscape Metrics}

Figure 6 shows pattern of the Metrics LPI, LSI, ENN_MN and AI as calculated by equations shown in Figure 2 using FRAGSTATS. Class (AI) and Landscape metrics (LPI, LSI and ENN_MN) were part of this calculation for Built-up patches to analyse spatial pattern and characteristics of urbanisation.

LPI depicting the compactness of Built-up patches is highest in NE zone of study area and it keeps increasing from year 1985 to 2015. SE is having negligible built-up patches in year 1985 as depicted in Figure 3 also keeping in line with the near to zero LPI value for SE in year 1985 in Figure 6.

LSI depicting the complexity of Built-up patches in Figure 6 is showing highest values for all zones in year 2015. It may be attributed to generation of Overlying type of urban growth in year 2015 in almost all 4 zones of study area. Higher values of LSI suggests that patches area having more irregular shape and vice-versa, which can happen due to generation of dispersed growth and formation of new patches.

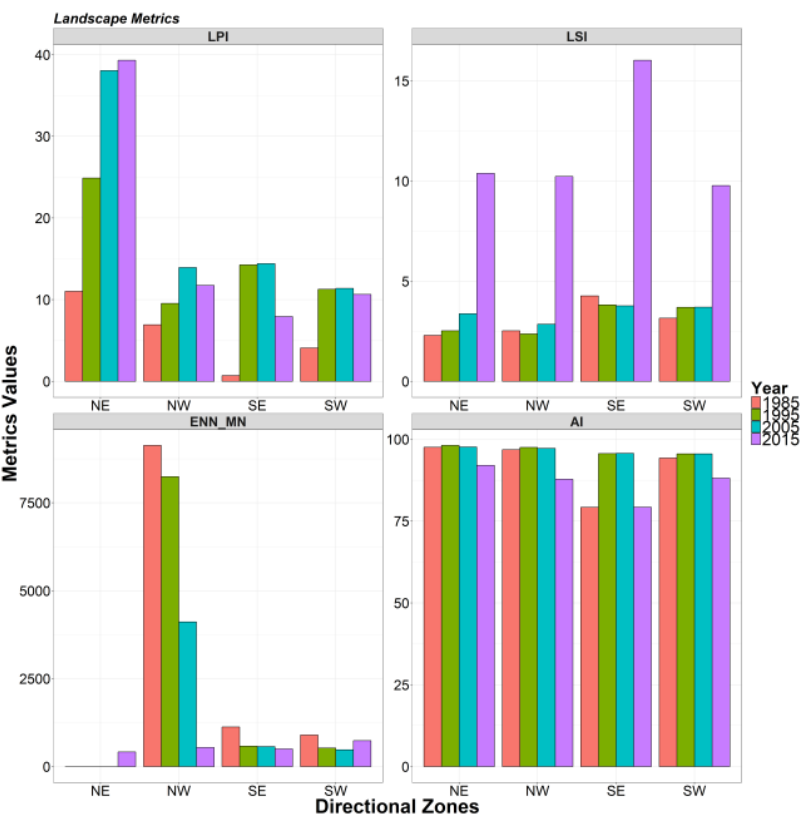

Figure 6. Landscape Metrics for Built-up patches.

ENN_MN in Figure 6 shows that NW zone is having maximum centrality of Built-up patches in stud area and that too in year 1985 after which it keeps decreasing. Higher value of ENN_MN tells that patches are lying at closer to the centre of urbanisation in study area which is the reason of lower values of all other zones in all years from 1985 to 2015 as urbanisation is continuously spreading in direction away from centre.

AI shows the porosity of patches in study area, i.e. closeness of other land use classes to built-up patches. Higher values are found for each zone in each year for built-up patches in study area meaning that built-up patches are surrounded by one or other classes.

\subsection{Shannon's Entropy $\left(H_{n}\right)$}

Shannon's Entropy $\left(H_{n}\right)$ values for study area from year 1985 to 2015 area shown in Figure 7 as below. Total no. of zones being 4 in study area $\log (n)$ is 1.38694 for this study and none of the value in Figure 7 is closer to this value of $\log (n)$. Although for 
all the zones except SE, values of entropy are similar in each year and away from $\log (n)$, showing convergence of built-up patches in respective zones. For SE zone, in year 1985 entropy values is less but increases for year 1995 and then keeps on decreasing but being not so different than previous year values i.e. almost being same. It falls in same line with results from classification maps from Figure 3, where in year 1985 SE is having very less built-up patches but after that urbanisation takes place in zone in subsequent years being close to centre of urbanisation.

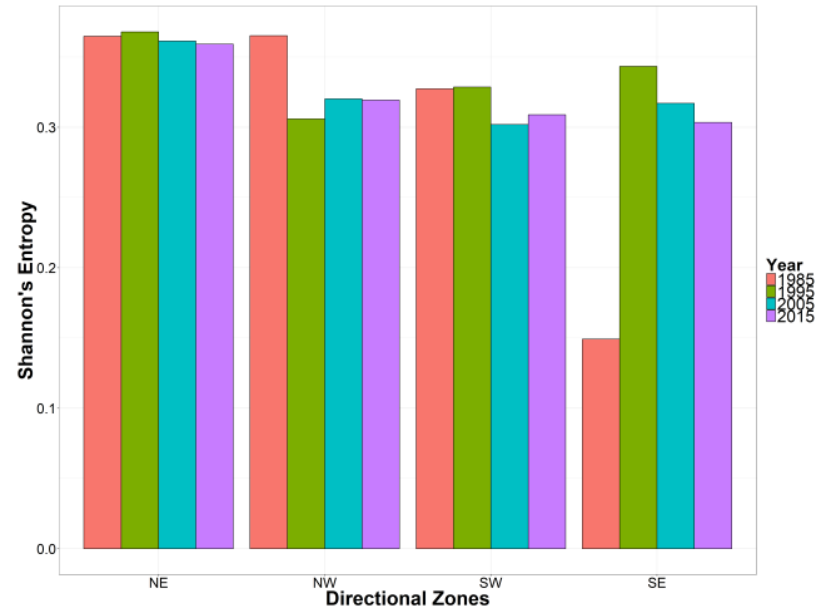

Figure 7. Types of Urban growth in different years.

Entropy values keeps increasing from year 1985 to 2015 . It is lowest in year 1985 with entropy value of 0.17215 and then a sudden increase occurs in year 1995 up to 0.286125 . In year 2005 and 2015 it is almost same being 0.317313 and 0.324815 respectively, but in none of the years it is close to $\log (n)$ value. It tells the convergent nature of urbanisation in study area over the period of study. Figure 3 also suggests that urbanisation is accumulated at centre of study area only. Urbanisation at boundary of study area of LDA is still to take place in nearby future.

\section{CONCLUSIONS}

Study successfully shows the relation between different parameters and characteristics of urbanisation over a duration of change. Spatio-temporal analysis of urbanisation helps in understanding the behaviour of urbanisation in upcoming times. Planners can be greatly benefitted using the study of urbanisation. Directional study of urbanisation is helpful in understanding the growth of urbanisation in particular direction. Greater overlying urban growth can be sustained using allocating a specific location for urbanisation.

Land use change analysis helps in understanding the trend of change in land use classes in study area. Over a larger period of time this type of study can be fruitful in implying the laws regarding land use by city dwellers.

Landscape metrics help in keeping the check on urbanisation. Porosity and centrality can keep in check of much needed Urban Green Space (UGS) in urban area. Similarly, complexity and compactness of built-up patches in urbanisation pattern analysis helps in mitigating the density part of it which can be major factor for communication networks, resource allocation in city.
Shannon's Entropy value helps in understanding the pattern of expansion of urbanisation over a period of time in different directions. More area for urbanisation can be considered by planner if Entropy value is large to accommodate large residential area and if value of Entropy is small, remaining space can be considered for environment planning such as cooling effects and aesthetics.

\section{REFERENCES}

Berling-Wolff, S., \& Wu, J., 2004a. Modeling urban landscape dynamics: A case study in Phoenix, USA. Urban ecosystems, 7(3), 215-240.

Berling-Wolff, S., \& Wu, J., 2004b. Modeling urban landscape dynamics: A review. Ecological Research, 19(1), 119-129.

Bhatta, B., 2009. Analysis of urban growth pattern using remote sensing and GIS: a case study of Kolkata, India. International Journal of Remote Sensing, 30(18), 4733-4746.

Buchhorn, M., Smets, B., Bertels, L., De Roo, B., Lesiv, M., Tsendbazar, N.E., Linlin, L., Tarko, A., 2020. Copernicus Global Land Service: Land Cover 100m: Version 3 Globe 2015-2019, Product User Manual; Zenodo, Geneve, Switzerland, September 2020; doi: 10.5281/zenodo.3938963.

Camagni, R., Gibelli, M. C., \& Rigamonti, P., 2002. Urban mobility and urban form: the social and environmental costs of different patterns of urban expansion. Ecological economics, 40(2), 199-216.

Huang, J., Lu, X. X., \& Sellers, J. M. 2007. A global comparative analysis of urban form: Applying spatial metrics and remote sensing. Landscape and urban planning, 82(4), 184-197.

Jat, M. K., Garg, P. K., \& Khare, D., 2008. Modelling of urban growth using spatial analysis techniques: a case study of Ajmer city (India). International Journal of Remote Sensing, 29(2), 543-567.

Ji, W., Ma, J., Twibell, R. W., \& Underhill, K., 2006. Characterizing urban sprawl using multi-stage remote sensing images and landscape metrics. Computers, Environment and Urban Systems, 30(6), 861-879.

Jiang, F., Liu, S., Yuan, H., \& Zhang, Q. 2007. Measuring urban sprawl in Beijing with geo-spatial indices. Journal of Geographical Sciences, 17(4), 469-478.

Li, C., Li, J., \& Wu, J., 2013. Quantifying the speed, growth modes, and landscape pattern changes of urbanization: a hierarchical patch dynamics approach. Landscape ecology, 28(10), 1875-1888.

Liu, X., Li, X., Chen, Y., Tan, Z., Li, S., \& Ai, B., 2010. A new landscape index for quantifying urban expansion using multitemporal remotely sensed data. Landscape ecology, 25(5), 671682 .

Liu, X., Ma, L., Li, X., Ai, B., Li, S., \& He, Z., 2014. Simulating urban growth by integrating landscape expansion index (LEI) and cellular automata. International Journal of Geographical Information Science, 28(1), 148-163. 
Liu, Z., He, C. and Wu, J., 2016. General spatiotemporal patterns of urbanization: An examination of 16 world cities. Sustainability, 8(1), p.41.

McGarigal, K., \& Marks, B. J., 1995 FRAGSTATS: spatial pattern analysis program for quantifying landscape structure (Gen. Tech. Rep. PNW-GTR-351. Portland, OR: U.S. Department of Agriculture, Forest Service, Pacific Northwest Research Station, 122 p.) doi:10.2737/PNW-GTR-351

Maimaiti, B., Ding, J., Simayi, Z., \& Kasimu, A., 2017. Characterizing urban expansion of Korla City and its spatialtemporal patterns using remote sensing and GIS methods. Journal of Arid Land, 9(3), 458-470.

Ramachandra, T. V., \& Aithal, B. H., 2013. Urbanisation and sprawl in the Tier II city: metrics, dynamics and modelling using spatio-temporal data. International Journal of Remote Sensing Applications, 3(2), 65-74.

Ramachandra, T. V., Aithal, B. H., \& Sanna, D. D., 2012. Insights to urban dynamics through landscape spatial pattern analysis. International Journal of Applied Earth Observation and Geoinformation, 18, 329-343.

Ramachandra, T. V., Sellers, J., Bharath, H. A., \& Vinay, S., 2019. Geo-visualization of landscape dynamics in the proposed mega industrial corridor. Environmental monitoring and assessment, 191(3), 1-18.

Roy, P.S., Meiyappan, P., Joshi, P.K., Kale, M.P., Srivastav, V.K., Srivasatava, S.K., Behera, M.D., Roy, A., Sharma, Y., Ramachandran, R.M. and Bhavani, P., Decadal Land Use and Land Cover Classifications across India, 1985, 1995, 2005, 2016. ORNL DAAC, Oak Ridge, Tennessee, USA. doi:10.3390/rs70302401

Sapena, M., \& Ruiz, L. A., 2015. Analysis of Urban Development by Means Of Multi-Temporal Fragmentation Metrics From Lulc Data. International Archives of the Photogrammetry, Remote Sensing \& Spatial Information Sciences, Berlin, Germany, Volume XL-7/W3.

Sun, C., Wu, Z. F., Lv, Z. Q., Yao, N., \& Wei, J. B., 2013. Quantifying different types of urban growth and the change dynamic in Guangzhou using multi-temporal remote sensing data. International Journal of Applied Earth Observation and Geoinformation, 21, 409-417.

Wilson, E. H., Hurd, J. D., Civco, D. L., Prisloe, M. P., \& Arnold, C., 2003. Development of a geospatial model to quantify, describe and map urban growth. Remote sensing of environment, 86(3), 275-285.

Wu, J., Jenerette, G. D., Buyantuyev, A., \& Redman, C. L., 2011. Quantifying spatiotemporal patterns of urbanization: The case of the two fastest growing metropolitan regions in the United States. Ecological Complexity, 8(1), 1-8.

Wu, Y., Li, S., \& Yu, S., 2016. Monitoring urban expansion and its effects on land use and land cover changes in Guangzhou city, China. Environmental monitoring and assessment, 188(1), 54.

Xu, C., Liu, M., Zhang, C., An, S., Yu, W., \& Chen, J. M., 2007. The spatiotemporal dynamics of rapid urban growth in the Nanjing metropolitan region of China. Landscape ecology, 22(6), 925-937.

Yang, J., Li, S., \& Lu, H., 2019. Quantitative influence of landuse changes and urban expansion intensity on landscape pattern in Qingdao, China: Implications for urban sustainability. Sustainability, 11(21), 6174. 